\title{
Montesquieu, Saggio sulle cause che possono agire sugli spiriti e sui caratteri
}

\section{Franco Piva}

\section{Q OpenEdition}

1 Journals

\section{Edizione digitale}

URL: http://journals.openedition.org/studifrancesi/30303

DOI: 10.4000/studifrancesi.30303

ISSN: 2421-5856

\section{Editore}

Rosenberg \& Sellier

\section{Edizione cartacea}

Data di pubblicazione: 1 avril 2006

Paginazione: 157

ISSN: 0039-2944

\section{Notizia bibliografica digitale}

Franco Piva, «Montesquieu, Saggio sulle cause che possono agire sugli spiriti e sui caratteri», Studi Francesi [Online], 148 (XLX | I) | 2006, online dal 30 novembre 2015, consultato il 19 avril 2021. URL: http://journals.openedition.org/studifrancesi/30303; DOI: https://doi.org/10.4000/studifrancesi. 30303

Questo documento è stato generato automaticamente il 19 avril 2021.

\section{(c)}

Studi Francesi è distribuita con Licenza Creative Commons Attribuzione - Non commerciale - Non opere derivate 4.0 Internazionale. 


\title{
Montesquieu, Saggio sulle cause che possono agire sugli spiriti e sui caratteri
}

\author{
Franco Piva
}

\section{NOTIZIA}

MONTESQUIEU, Saggio sulle cause che possono agire sugli spiriti e sui caratteri, a cura di Domenico Felice, Pisa, Edizioni ETS, 2004 («Tracce», 22), pp. 85.

1 «Composto presumibilmente tra il 1736 e il 1743, cioè negli stessi anni in cui Montesquieu lavora alla stesura originaria dell'Esprit des Lois, l'Essai sur les causes qui peuvent affecter les esprits et les caractères è senza dubbio - osserva Domenico Felice - il più importante tra gli scritti lasciati inediti e incompiuti dal filosofo francese. La sua importanza (non sempre adeguatamente colta dagli interpreti) risiede essenzialmente nel fatto che esso contiene la più esauriente formulazione - prima della sistemazione definitiva messa a punto nella terza parte dell'opus magnum (libri XIV-XIX) - dell'esprit général d'une nation o d'un peuple, ossia della categoria più originale, accanto al concetto di dispotismo come forma autonoma di governo e al principio dell'autonomia della giustizia, tra le innumerevoli elaborate da Montesquieu e di quella che ha goduto, assieme alla sua dottrina della divisione dei poteri, di maggior fortuna fino ai nostri giorni».

Dell'Essai Domenico Felice propone una traduzione sobria ed elegante insieme, condotta sul testo del manoscritto conservato presso la Beinecke Rare Book and Manuscript Library dell'Università di Yale. Essa è preceduta da un'ampia Introduzione nella quale il Curatore esamina le ragioni addotte da Montesquieu a sostegno della sua teoria; in particolare i due gruppi di cause che, a detta del philosophe di La Brède, agiscono sulla formazione dell'esprit général d'une nation: quelle fisiche e quelle morali, nonché il loro reciproco concatenarsi, con effetti che fanno sì che l'uomo sia nei diversi contesti fisici e morali in cui si trova a vivere quello che storicamente e geograficamente è. Con un'intuizione la quale, anziché ridursi ad un puro e semplice determinismo, conserva 
tutta la sua validità. «Il significato ultimo - o se si preferisce, il messaggio più duraturo - di questo importante testo montesquieuiano risiede proprio in questo - osserva infatti in conclusione Domenico Felice pensando alla nostra realtà - ovvero nel fatto che tutto, in qualche modo, ci riguarda o ci condiziona: le variazioni della temperatura atmosferica e il tipo di persone che frequentiamo: il regime del venti e i libri (buoni o cattivi) che leggiamo; l'aria che respiriamo e i viaggi che intraprendiamo; le proprietà chimico-fisiche dei luoghi dove risiediamo e lo stile di vita che abbiamo adottato o che ci siamo autoimposto; la qualità dei cibi che mangiamo e il genere di professione che esercitiamo; in una parola, tutto ciò che appartiene, o si riferisce, al mondo tanto naturale quanto storico-culturale entro cui la sorte ci ha collocati, o che abbiamo scelto come nostra dimora». 